\title{
Experience and Description: Exploring Two Paths to Knowledge
}

Current Directions in Psychological Science

2018, Vol. 27(2) 123-128

(C) The Author(s) 2018

Reprints and permissions:

sagepub.com/journalsPermissions.nav DOI: $10.1177 / 0963721417740645$ www.psychologicalscience.org/CDPS

@SAGE

\section{Ralph Hertwig', Robin M. Hogarth ${ }^{2,3}$, and Tomás Lejarraga ${ }^{1,4}$}

${ }^{1}$ Max Planck Institute for Human Development, Center for Adaptive Rationality, Berlin, Germany; ${ }^{2}$ Departament d'Economia i Empresa, Universitat Pompeu Fabra; ${ }^{3}$ Barcelona Graduate School of Economics; and ${ }^{4}$ Departament d'Economia de l'Empresa, Universitat de les Illes Balears

\begin{abstract}
Experience and description are powerful ways of learning and adaptation. Recently, evidence has shown that these can imply systematically distinct cognitions and behaviors. However, there has been little integrative conceptual work. Drawing on different lines of research, we characterize experience and description, sketch the factors that influence learning from them, and suggest how to reconcile previously disparate research. We propose that much can be gained by studying the behavioral, cognitive, and hedonic implications of description- and experience-based learning in parallel.
\end{abstract}

\section{Keywords}

decisions from experience and description, learning, adaptation, intuitive statistician, heuristics and biases

A man who carries a cat by the tail learns something he can learn in no other way.

In the beginning was the act!

- Mark Twain ${ }^{1}$

-Johann Wolfgang von Goethe (1808/1871, p. 40)

The long-standing investigation of risky choice, key to the development of mathematical expectation and theories of rational and descriptive decision making, has drawn on two distinct experimental paradigms. In one, people are presented with explicit descriptions of choice options, such as the probabilities of gaining or losing specific amounts of money. In the other, instead of being presented with such descriptions, people can learn the properties of choice options through experience by sequentially sampling outcomes. Whereas the objective properties of the payoff distributions are, in theory, the same in both cases, behavior differs (Barron \& Erev, 2003; Weber, Shafir, \& Blais, 2004; see also Hertwig, 2015). This difference has been labeled the description-experience gap (Hertwig, Barron, Weber, \& Erev, 2004; Wulff, Mergenthaler-Canseco, \& Hertwig, 2018). Our goal in this article is to elaborate on this distinction in order to highlight differences between the roles of description and experience in human inference. By description, we mean that the decision maker has been provided with a full or partial symbolic summary representation of a situation, whereas experience entails having reached an understanding based on interaction with the environment.

To appreciate the importance of this distinction, compare the following conclusions separated by only a few years. In their review "Man as an Intuitive Statistician," Peterson and Beach (1967) concluded that

experiments that have compared human inferences with those of statistical man [making optimal inferences] show that the normative model provides a good first approximation for a psychological theory of inference. Inferences made by subjects are influenced by appropriate variables and in appropriate directions. (pp. 42-43)

In contrast, in their seminal article, "Judgment Under Uncertainty: Heuristics and Biases," Tversky and Kahneman (1974) concluded that the normative models fail to approximate what people do. Instead, they write,

\section{Corresponding Author:}

Tomás Lejarraga, Universitat de les Illes Balears, Departament d'Economia de l'Empresa, Palma de Mallorca, Spain

E-mail: tomas.lejarraga@uib.eu 
people rely on a limited number of heuristic principles by which they reduce the complex tasks of assessing likelihoods and predicting values to simpler judgmental operations. In general, these heuristics are quite useful, but sometimes they lead to severe and systematic errors. (p. 1124)

These conflicting conclusions may be at least partly attributable to differences in the researchers' experimental protocols that map onto the descriptionexperience distinction. Specifically, many studies in the pre-heuristics-and-biases days of behavioral-decisionmaking research (conducted by Ward Edwards and myriad colleagues) tested people's statistical intuitions and choices in the context of experience-based learning environments. The title of a publication by Edwards (1961) in the Journal of Experimental Psychology makes this clear: "Probability learning in 1000 trials." In contrast, the heuristics-and-biases protocol typically involves description-based scenarios requiring little learning. Recent evidence supports the thesis that this difference matters. Hogarth and Soyer (2011) specifically contrasted the effects of learning from description and experience on responses to several well-known probabilistic tasks. Participants' responses reflected differences in how they learned. Learning from experience led to more normatively appropriate responses than learning from description. Relatedly, Wulff et al. (2018) observed more normative choices in response to experience-based rather than description-based payoff distributions.

The description-experience distinction has also been identified as a key variable to understand different performance in causal reasoning. Rehder and Waldmann (2017) examined causal reasoning in conditions where the causal relationships were verbally described and in conditions where they were learned from samples of data. Consistent with the view of man as an intuitive statistician, Rehder and Waldmann observed stronger deviations from normative predictions when causes were learned from verbal descriptions than when they were learned from experience. People "were overall relatively competent in estimating probabilities from data" (p. 255). Similarly, Nelson, McKenzie, Cottrell, and Sejnowski (2010) investigated how accurately people categorize stimuli on the basis of descriptive or experiential cues. Here, again, there was a description-experience gap.

Experiential learning is possibly the most important source of adaptation and a building block of intelligence (March, 2010). But, of course, not all of an individual's knowledge results from experience. It is greatly augmented by others' strokes of genius or their systematic observation and engagement with the environment. This knowledge is represented, accumulated, and communicated through spoken and written symbols, and thus description is another powerful source of individual and collective adaptation (Richerson \& Boyd, 2005). Hardly any aspect of modern life-from technology, science, and commerce to arts and the World Wide Web-is conceivable without processing symbolic descriptions. They allow us to share knowledge and access accumulated wisdom, thus liberating us from the bounds of individual experience (Schmandt-Besserat, 1996). Yet descriptions are abstractions and cannot fully substitute for an individual's experience with the environment. Experience and description are two complementary but not equivalent ways of learning.

It is timely to compare and contrast the two ways of learning. Drawing on different lines of research, we characterize the essence of experience and description, sketch the factors that influence learning from them, and suggest how to reconcile previously disparate findings. Before doing so, we emphasize that although we speak of description and experience as a dichotomy, we think of them as an important-and illuminatingcontinuum (e.g., learning on the basis of a description can also form an experiential episode) that merits attention. We also emphasize that we aim to capture what discerns experience and description, without offering formal models. The available models cannot do justice to the wealth and depth of differences.

\section{Experience and Learning From Experience}

We conceptualize experience as a vector of information used for learning. According to this view, experience is the process and the result of living through events. For example, in the aforementioned experimental paradigm, participants experience outcomes by sequentially sampling from payoff distributions. Although undergoing an experience may be effortful, learning is relatively effortless. We experience events and automatically make inferences, abstractions, or generalizations. Experience is concrete as opposed to symbolic, and it has immediate authority for the experiencing individual. It is empirical and rests on the certitude of events that have actually occurred. Experience has coordinates in time and space. Although anchored in the reality of the individual, its interpretation can be ambiguous (e.g., when samples are small or the causal structure of experience is complex). Experience evaluates past actions and guides future actions (March, 2010). Repeated experiences provide the foundations for the acquisition of skills, for example, learning to ride a bicycle, ski, type, or perform surgery, that could not be learned, or at least not exclusively, on the basis of descriptions (see Ryle's, 1945, related distinction between "knowing how" and "knowing that"). 
The consequences of experience can be epistemic. On carrying the cat by its tail, Mark Twain immediately acquired new knowledge about the cat's preferences. The consequences of experience can also be material, as Twain realized when scratched by the cat. Experiences with material consequences impact future behavior more than those without (Camerer \& Hogarth, 1999; Malmendier \& Nagel, 2011; Skinner, 1950). Experiences can vary in their hedonic consequences. They can be pleasant or, as in Twain's interaction with the cat, unpleasant. People seek to repeat experiences with positive hedonic and material consequences and avoid negative ones, leading in interaction with the environment to a rich repertoire of predictable human behaviors (Denrell, 2005, 2007).

Although individuals can, to some extent, choose their experiences, the process of learning from experience is tacit. This has two consequences. First, it is hard not to learn from experience. For example, it would be hard not to learn the statistical regularities of conditional probabilities in natural language (e.g., Aslin, Saffran, \& Newport, 1998). Second, it is also hard to learn from the lack of experience. For example, people often fail to act on the risk of rare events because of their frequent nonoccurrence (Taleb, 2007; Weber, 2006): "What you see is all there is" (Kahneman, 2011, p. 86). To learn from events that did not occur but could have occurred requires the replacement of actual experience with imagination, with all the problems that such a substitution may involve. Second, the tacit nature of learning from experience can make it difficult to achieve an accurate cognitive representation of situations, which, in turn, might enable better decisions. Relatedly, the immediate persuasiveness of experience can outweigh important elements from descriptions. Experience can lead to acquiring naive beliefs (Einhorn \& Hogarth, 1978; Hogarth, Lejarraga, \& Soyer, 2015) because people typically lack metacognitive insight (Fiedler, 2000).

\section{Description and Learning From Description}

We characterize description as externalized symbolic representations of knowledge. Descriptions pertain to any kind of knowledge, such as propositional, causal, procedural, or episodic. Description can also refer to things nobody has ever experienced (Pinker, 2007). Symbolic representations can be written or spoken words, numbers, or images. Internal abstractions of the world, for instance, mental models, are not descriptions. Yet when these leave the individual mind in the form of, for example, stories, warnings, or testimony, they become descriptions and accessible to others. Descriptions necessarily reduce the multidimensionality of an individual's experience (in the same way that memory does; see James, 1890); otherwise they cannot be efficient representations of knowledge.
Descriptions have an author-a speaker, writer, or producer of symbols. Through descriptions, the author enables his or her experience and knowledge to travel and be shared. Descriptions need not be bounded by time and place and can inform individuals about hypothetical histories or very unlikely events. Merely mentioning or presenting an event or focusing people's attention on one event through an explicit description, however, can (unduly) increase the event's psychological impact (Kahneman \& Tversky, 1979).

Some descriptions, such as spoken words, fade quickly; others, such as written words, may be permanent. Descriptions can inform us about possible consequences of actions without needing to pay the price of experiencing them. Learning from description empowers cultural evolution (Richerson \& Boyd, 2005) and is, for the most part, a unique human competence.

\section{Influences on Learning From Experience}

Learning from experience is influenced by both human characteristics and the structure of the environment. For instance, psychological distance matters (Trope \& Liberman, 2003). The "closer" the individual is to the experience, the greater the effect. Individuals are more influenced by something that happens to them or their in-group as opposed to other individuals or groups. Furthermore, affordances in the environment matter (Gibson, 1977). Active learning, that is, being in control of the learning episode and thus self-directing the flow of experience, is more likely to result in superior acquisition than passive learning, where, in contrast, information is provided by the social or physical environment, and the timing and sequence of presentation is not under our immediate control (Gureckis \& Markant, 2012; Markant \& Gureckis, 2014). Another critical factor centers on how the structure of the learning environment matches the setting in which actions need to be taken (i.e., the "target setting"; Hogarth et al., 2015, p. 381). People act on the plausible assumption that the future resembles the past, but this assumption does not always hold. Finally, the environment often affords only small learning samples, thereby rendering generalization problematic (Fiedler, 2000; March, 2010).

\section{Influences on Learning From Description}

News informs, poems move, and scientific reports reveal. As said before, descriptions need an author and thus involve assumptions and intentions. Even in the opening example, where choice options are simple, assumptions play a role. For example, the experimenter can represent the chances of events as single-event probabilities, relative frequencies, or pie charts, but this choice depends on his or her assumptions about how 
these formats affect responses. The author interprets and proposes a view. A weather forecast, for example, states the daily mean temperature. The forecaster thus wittingly or unwittingly imposes his or her assumption that this quantity is more important than, for instance, the variance of the temperature. The author can also actively manipulate. For example, Colgate's slogan that $80 \%$ of dentists recommended their brand fails to mention that the dentists surveyed could choose to recommend several brands-not just one (http://news.bbc .co.uk/2/hi/uk_news/6269521.stm).

Authors can represent descriptions in various ways. People learn better from representations that are transparent, clearly exposing the nature of the problem (Hoffrage, Lindsey, Hertwig, \& Gigerenzer, 2000). Different descriptions of the same information can lead to different cognitions and behaviors. The evolution of the human mind has been shaped by the experience of the natural environment. Therefore, descriptive formats that approximate experiences are more likely to be easily processed (Cosmides \& Tooby, 1996). For example, metaphors gain their power by evoking experience. Moreover, people reason better when statistical contingencies are presented as natural frequencies as opposed to single-event probabilities (Hoffrage et al., 2000). Relative to experience-based learning, descriptionbased learning is a much more recently evolved cognitive capacity. In fact, some symbolic descriptions, such as statements of probabilities, are a cultural invention of the Enlightenment.

Another potential problem, one shared with experience, is that the meaning of a description requires interpretation. Logically or mathematically equivalent descriptions-for instance, a glass is half full or half empty-can evoke different mental representations and prompt opposite conclusions (Feynman, 1967). The former implies that the glass was previously empty, and against this reference point, the current state suggests a gain. The latter implies that the glass was previously full (Sher \& McKenzie, 2006), and against this past state, the current state suggests a loss. By choosing to describe a state of the world, the author can steer the reasoning and the behavior of the recipient of a description in different directions.

\section{Implications for Future Research: A Comparative Approach}

Learning from experience and from description are important ways of achieving intelligence and adaptation. For decades, they have been studied in isolation, and sometimes conflicting conclusions about human performance have been drawn. We highlighted differences in paradigms for studying probabilistic and causal reasoning at the outset. To this, we add an observation by developmental psychologist Gopnik (2014), who wondered, "Why are grown-ups often so stupid about probabilities when even babies and chimps can be so smart?" (para. 9). Her question pertained to the observation that whereas studies demonstrate that babies are good intuitive statisticians, surprisingly capable of statistical learning and judgment (see Schulze \& Hertwig, 2017), the statistical cognitions of adults have been found lacking. As Tversky and Kahneman (1983) put it, adults' "intuitive judgments of all relevant marginal, conjunctive, and conditional probabilities are not likely to be coherent, that is, to satisfy the constraints of probability theory" (p. 313).

One possible key to this conundrum is that babies, unlike adults, cannot yet operate on the basis of symbolic descriptions of probabilistic information. Consequently, babies' good statistical intuitions are observed in the context of experience-based experimental paradigms, whereas adults' apparent incompetence has commonly been inferred from one-shot description-based tasks (e.g., the Linda problem, the engineer-lawyer problem, the maternity ward problem; Kahneman, 2011), with no experiential learning required or permitted.

Experientially interacting with the world affords a multitude of concurrent dimensions of information (e.g., sensory, motoric, or affective) that symbolic descriptions lack or can convey only in an impoverished form. For instance, moment-to-moment experience can be accompanied by affective states that shape people's preferences and behaviors. When people leave the experiential and affective "hot state," they are prone to underestimate the influence of affect, a hot-cold empathy gap (e.g., Loewenstein, 2005). This gap is, of course, not identical with the description-experience gap. Descriptions can also elicit strong emotionsremember the shocking image of the drowned Syrian boy that epitomized the tragic plight of refugees (Slovic, Västfjäll, Erlandsson, \& Gregory, 2017). Yet immediate experience, ceteris paribus, has more potential to trigger hot affective states than description, removed by some degrees of abstraction. Not infrequently, experimental demonstrations of the hot-cold empathy gap contrast description and experience (e.g., Figner, Mackinlay, Wilkening, \& Weber, 2009).

Although learning from experience and description are distinct processes, they frequently co-occur. Understanding how they interact offers new insights into societally important issues, such as risk communications and warnings. Sometimes people have experienced many safe encounters with a risky event before being warned (e.g., episodes of unprotected sex without contracting a disease). Sometimes they may be blank slates with little or no immediate experience about the risk in question. In the former, the rich experience to the contrary may abrogate the warning. In the latter, the experiential void 
cedes the field to the description-based warning, possibly resulting in disproportional responses to both authorized and unauthorized warnings about issues such as terrorist threat, vaccines causing autisms, genetically modified food, or the H1N1 influenza pandemic. We suggest that a better understanding of the intricate interplay of description and experience may offer novel insights into why and when risk warnings are ineffective or, on the contrary, too effective (Barron, Leider, \& Stack, 2008; Weber, 2006).

To conclude, like most dichotomies, the distinction between experience- and description-based learning is a crude simplification. However, as we have shown, paying attention to this distinction leads to new psychological insights and research questions. We therefore propose that much can be gained by studying description- and experience-based learning in parallelnot just in research on risky choice but far beyond.

\section{Recommended Reading}

Hertwig, R., \& Erev, I. (2009). The description-experience gap in risky choice. Trends in Cognitive Sciences, 13, 517-523. A review of the literature on the descriptionexperience gap.

March, J. G. (2010). (See References). An in-depth reflection on the nature of learning from experience.

Peterson, C. R., \& Beach, L. R. (1967). (See References). A review of adult's intuitive statistical reasoning summarizing the research of the first two decades of behavioral decision research.

Tversky, A., \& Kahneman, D. (1974). (See References). The canonical article outlining the research program on heuristics and biases in intuitive statistical reasoning of adults.

Weber, E. U. (2006). (See References). An impressive example of the relevance of the description-experience distinction for an important societal issue, the world's response to climate change and lack thereof.

\section{Acknowledgments}

All three authors contributed equally to this article, and the order of authorship was determined alphabetically. Tomás Lejarraga is now at the Departament d'Economia de l'Empresa, Universitat de les Illes Balears. We thank Klaus Fiedler for challenging our reasoning.

\section{Declaration of Conflicting Interests}

The author(s) declared that there were no conflicts of interest with respect to the authorship or the publication of this article.

\section{Note}

1. This saying is the popularized version of a passage in Mark Twain's (1894) Tom Sawyer Abroad:

The person that had took a bull by the tail once had learnt sixty or seventy times as much as a person that hadn't, and ... a person that started in to carry a cat home by the tail was gitting knowledge that was always going to be useful to him, and warn't ever going to grow dim or doubtful. (p. 154)

\section{References}

Aslin, R. N., Saffran, J. R., \& Newport, E. L. (1998). Computation of conditional probability statistics by 8-month-old infants. Psychological Science, 9, 321-324.

Barron, G., \& Erev, I. (2003). Small feedback-based decisions and their limited correspondence to description-based decisions. Journal of Behavioral Decision Making, 16, 215-233.

Barron, G., Leider, S., \& Stack, J. (2008). The effect of safe experience on a warning's impact: Sex, drugs, and rockn-roll. Organizational Behavior and Human Decision Processes, 106, 125-142.

Camerer, C. F., \& Hogarth, R. M. (1999). The effects of financial incentives in experiments: A review and capital-laborproduction framework. Journal of Risk and Uncertainty, 19, 7-42.

Cosmides, L., \& Tooby, J. (1996). Are humans good intuitive statisticians after all? Rethinking some conclusions from the literature on judgment under uncertainty. Cognition, $58,1-73$.

Denrell, J. (2005). Why most people disapprove of me: Experience sampling in impression formation. Psychological Review, 112, 951-978.

Denrell, J. (2007). Adaptive learning and risk taking. Psychological Review, 114, 177-187.

Edwards, W. (1961). Probability learning in 1000 trials. Journal of Experimental Psychology, 62, 385-394.

Einhorn, H. J., \& Hogarth, R. M. (1978). Confidence in judgment: Persistence of the illusion of validity. Psychological Review, 85, 395-416.

Feynman, R. (1967). The character of physical law. Cambridge, MA: MIT Press.

Fiedler, K. (2000). Beware of samples! A cognitive-ecological sampling approach to judgment biases. Psychological Review, 107, 659-676.

Figner, B., Mackinlay, R. J., Wilkening, F., \& Weber, E. U. (2009). Affective and deliberative processes in risky choice: Age differences in risk taking in the Columbia Card Task. Journal of Experimental Psychology: Learning, Memory, and Cognition, 35, 709-730.

Gibson, J. J. (1977). The theory of affordances. In R. Shaw \& J. Bransford (Eds.), Perceiving, acting and knowing: Toward an ecological psychology (Vol. 27, pp. 67-82). Hillsdale, NJ: Erlbaum.

Goethe, J. W. (1871). Faust: A tragedy. Part I (B. Taylor, Trans.). Boston, MA: James Osgood. (Original work published 1808)

Gopnik, A. (2014, January 10). The surprising probability gurus wearing diapers. The Wall Street Journal. Retrieved from http://www.wsj.com/articles/SB10001424052702303 393804579308662389246416

Gureckis, T. M., \& Markant, D. B. (2012). Self-directed learning: A cognitive and computational perspective. Perspectives on Psychological Science, 7, 464-481.

Hertwig, R. (2015). Decisions from experience. In G. Keren \& G. Wu (Eds.), The Wiley Blackwell handbook of judgment 
and decision making. (Vol. 1, pp. 240-267). Chichester, England: Wiley-Blackwell.

Hertwig, R., Barron, G., Weber, E. U., \& Erev, I. (2004). Decisions from experience and the effect of rare events in risky choice. Psychological Science, 15, 534-539.

Hoffrage, U., Lindsey, S., Hertwig, R., \& Gigerenzer, G. (2000). Communicating statistical information. Science, 290, 2261-2262.

Hogarth, R. M., Lejarraga, T., \& Soyer, E. (2015). The two settings of kind and wicked learning environments. Current Directions in Psychological Science, 24, 379-385.

Hogarth, R. M., \& Soyer, E. (2011). Sequentially simulated outcomes: Kind experience versus nontransparent description. Journal of Experimental Psychology: General, 140, 434-463.

James, W. (1890). The principles of psychology (Volume 1). New York, NY: Holt. doi:10.1037/11059-000

Kahneman, D. (2011). Thinking, fast and slow. New York, NY: Macmillan.

Kahneman, D., \& Tversky, A. (1979). Prospect theory: An analysis of decision under risk. Econometrica, 47, 263-291.

Loewenstein, G. (2005). Hot-cold empathy gaps and medical decision making. Health Psychology, 24(4S), S49-S56.

Malmendier, U., \& Nagel, S. (2011). Depression babies: Do macroeconomic experiences affect risk taking? The Quarterly Journal of Economics, 126, 373-416.

March, J. G. (2010). The ambiguities of experience. Ithaca, NY: Cornell University Press.

Markant, D., \& Gureckis, T. M. (2014). Is it better to select or receive? Learning via active and passive hypothesis testing. Journal of Experimental Psychology: General, 143, 94-122.

Nelson, J. D., McKenzie, C. R. M., Cottrell, G. W., \& Sejnowski, T. J. (2010). Experience matters: Information acquisition optimizes probability gain. Psychological Science, 21, 960-969. doi:10.1177/0956797610372637

Peterson, C. R., \& Beach, L. R. (1967). Man as an intuitive statistician. Psychological Bulletin, 68, 29-46. doi:10.1037/ h0024722

Pinker, S. (2007). The stuff of thought: Language as a window into buman nature. New York, NY: Viking.

Rehder, B., \& Waldmann, M. R. (2017). Failures of explaining away and screening off in described versus experienced causal learning scenarios. Memory $\&$ Cognition, $45,245-260$.
Richerson, P. J., \& Boyd, R. (2005). Not by genes alone-how culture transformed human evolution. Chicago, IL: The University of Chicago Press.

Ryle, G. (1945). Knowing how and knowing that: The presidential address. Proceedings of the Aristotelian Society, $46,1-16$.

Schmandt-Besserat, D. (1996). How writing came about. Austin: University of Texas Press.

Sher, S., \& McKenzie, C. R. (2006). Information leakage from logically equivalent frames. Cognition, 101, 467-494.

Skinner, B. F. (1950). Are theories of learning necessary? Psychological Review, 57, 193-216.

Slovic, P., Västfjäll, D., Erlandsson, A., \& Gregory, R. (2017). Iconic photographs and the ebb and flow of empathic response to humanitarian disasters. Proceedings of the National Academy of Sciences, USA, 114, 640-644.

Schulze, C., \& Hertwig, R. (2017). Statistical intuitions: Smart babies, stupid adults? Manuscript submitted for publication.

Taleb, N. N. (2007). The black swan: The impact of the bighly improbable. New York, NY: Random House.

Trope, Y., \& Liberman, N. (2003). Temporal construal. Psychological Review, 110, 403-421.

Tversky, A., \& Kahneman, D. (1974). Judgment under uncertainty: Heuristics and biases. Science, 185, 1124-1131. doi:10.1007/978-94-010-1834-0_8

Tversky, A., \& Kahneman, D. (1983). Extensional versus intuitive reasoning: The conjunction fallacy in probability judgment. Psychological Review, 90, 293-315. doi:10.1037/0033-295X.90.4.293

Twain, M. (1894). Tom Sawyer abroad. New York, NY: C.S. Webster \& Company. Retrieved from https://archive.org/ details/tomsawyerabroad00twai

Weber, E. U. (2006). Experience-based and description-based perceptions of long-term risk: Why global warming does not scare us (yet). Climatic Change, 77, 103-120.

Weber, E. U., Shafir, S., \& Blais, A. R. (2004). Predicting risk sensitivity in humans and lower animals: Risk as variance or coefficient of variation. Psychological Review, 111, 430-445.

Wulff, D. U., Mergenthaler-Canseco, M., \& Hertwig, R. (2018). A meta-analytic review of two modes of learning and the description-experience gap. Psychological Bulletin, 144, 140-176. 